\title{
EFEKTIVITAS KOORDINASI ANTAR STAKEHOLDERS OLEH BADAN PENANGGULANGAN BENCANA DAERAH KOTA PADANG
}

\section{EFFECTIVENESS OF INTER-STAKEHOLDERS COORDINATION OF PADANG CITY REGIONAL DISASTER MANAGEMENT AGENCY}

\author{
Nesy Yulia Murni ${ }^{1}$ dan Zikri Alhadi² \\ 1,2 Jurusan Administrasi Publik/Pusat Kajian Kebijakan dan Pembangunan Sosial \\ Universitas Negeri Padang \\ Email: zikrialhadi@fis.unp.ac.id
}

Naskah Masuk: 20-04-2019

Naskah Diterima: 31-05-2019

Naskah Disetujui: 13-06-2019

\begin{abstract}
This study aims to determine the effectiveness of the performance of the Padang Disaster Management Agency in coordinating among stakeholders in disaster management in the city of Padang. The research method used in this study is qualitative research. Data collection techniques in this study were conducted by interview and documentation study. The research was conducted at the Padang Disaster Management Agency (BPBD) office, Padang Social Service office, Padang Search and Relief Agency office, and Padang Red Cross (PMI) Headquarters. The technique of selecting informants that the researchers used was purposive sampling. The results of the study showed that the function of coordination carried out by the BPBD of Padang City could be said to be effective. This is because all stakeholders are involved in handling disasters, especially during emergency response. Among the forms of coordination is the involvement of the Rapid Reaction Team (TRC) which plays a role in identifying disaster status so that handling can be quickly carried out. Furthermore BPBD along with relevant stakeholders also coordinated to carry out joint handling in providing assistance to disaster victims.
\end{abstract}

Keywords: Coordination, BPBD Kota Padang, Disaster Management

\begin{abstract}
ABSTRAK
Penelitian ini bertujuan untuk mengetahui efektivitas kinerja Badan Penanggulangan Bencana Daerah Kota Padang dalam melakukan koordinasi antar stakeholders penanggulangan bencana di Kota Padang. Metode penelitian yang peneliti gunakan dalam penelitian ini adalah penelitian kualitatif. Teknik pengumpulan data dalam penelitian ini dilakukan dengan wawancara dan studi dokumentasi. Penelitian ini dilakukan di kantor Badan Penanggulangan Bencana Daerah (BPBD) Kota Padang, kantor Dinas Sosial Kota Padang, kantor Badan Pencarian dan Pertolongan Padang, dan Markas Palang Merah Indonesia (PMI) Kota Padang. Teknik pemilihan informan yang peneliti gunakan adalah purposive sampling. Hasil penelitian menunjukkan bahwa fungsi koordinasi yang dilakukan oleh BPBD Kota Padang dapat dikatakan efektif. Hal ini dikarenakan semua stakeholders terlibat dalam penanganan bencana terutama ketika tanggap darurat. Diantaranya bentuk koordinasi adalah keterlibatan Tim Reaksi Cepat (TRC) yang berperan dalam mengidentifikasi status bencana sehingga penanganan dapat cepat dilakukan. Selanjutnya BPBD beserta stakeholders terkait juga berkoordinasi untuk melakukan penanganan bersama dalam memberikan bantuan kepada para korban bencana.
\end{abstract}

Kata kunci: Koordinasi, BPBD Kota Padang, Penanggulangan bencana

\section{PENDAHULUAN}

Kota Padang merupakan salah satu daerah yang rawan terhadap bencana
alam.Keadaan Kota Padang dapat

dilihat dari kajian risiko bencana Kota 
Padang, pada umumnya bencana di Kota Padang memiliki tingkat kerentanan yang tinggi, terutama bencana gempa bumi dan tsunami.Bencana gempa besar pernah terjadi di Kota Padang adalah gempa pada tahun 2009 yang banyak menimbulkan dampak buruk bagi Kota Padang.Selain gempa, bencana yang sering terjadi di Kota Padang adalah bencana banjir.Hal ini dikarenakan banyaknya pemukiman yang berada di daerah rendah dan di sepanjang aliran sungai. Beberapa bulan lalu tepatnya pada tanggal 02 november 2018, banjir masih melanda Kota Padang yang menyebabkan banyaknya daerah yang terkena dampak. Dampak tersebut dapat dilihat pada tabel berikut :

Tabel 1. Dampak Bencana Banjir Bulan November 2018 Di Kota Padang

\begin{tabular}{|c|c|c|c|c|}
\hline No. & Lokasi Terdampak & Kelurahan & Kecamatan & Keterangan \\
\hline 1 & RW 08 Perumnas Alai & Bungus Barat & $\begin{array}{l}\text { Bungus Teluk } \\
\text { Kabung }\end{array}$ & $\begin{array}{l}\text { - Ketinggian air } \pm 80 \mathrm{~cm} \mathrm{~s} / \mathrm{d} 100 \mathrm{~cm} \\
\text { - } \text { Mengancam } 1.500 \mathrm{Jiwa}(240 \mathrm{KK})\end{array}$ \\
\hline 2 & $\begin{array}{l}\text { RT } 02 \text { RW } 04 \text { Jarwai } \\
\text { Simpang } 4 \text { Bungus }\end{array}$ & Bungus Barat & $\begin{array}{l}\text { Bungus Teluk } \\
\text { Kabung }\end{array}$ & $\begin{array}{l}\text { - } 1 \text { anak hanyut terbawa arus air } \\
\text { (meninggal dunia) }\end{array}$ \\
\hline 3 & Kompelk Arai Pinang & Pegambiran Ampalu & Lubuk Begalung & - Ketinggian air hingga $\pm 30 \mathrm{~s} / \mathrm{d} 40 \mathrm{~cm}$ \\
\hline 4 & Komplek Griya Elok & Pegambiran Ampalu & Lubuk Begalung & - Ketinggian air hingga $\pm 30 \mathrm{~s} / \mathrm{d} 40 \mathrm{~cm}$ \\
\hline 5 & Batung Taba & Batung Taba & Lubuk Begalung & $\begin{array}{l}\text { - Ketinggian air hingga } \pm 70 \text { s/d } 100 \\
\mathrm{~cm}\end{array}$ \\
\hline 6 & $\begin{array}{l}\text { Perumahan Gurun } \\
\text { Laweh }\end{array}$ & Gurun Laweh & Lubuk Begalung & $\begin{array}{l}\text { - Ketinggian air hingga } \pm 70 \text { s/d } 100 \\
\mathrm{~cm}\end{array}$ \\
\hline 7 & RT 01 RW 04 & Koto Baru & Lubuk Begalung & $\begin{array}{l}\text { - Ketinggian air hingga } \pm 30 \mathrm{~s} / \mathrm{d} 40 \mathrm{~cm} \\
\text { - } 50 \mathrm{KK} \text { Terdampak banjir }\end{array}$ \\
\hline 8 & $\begin{array}{l}\text { Depan PAUD Wisma } \\
\text { Utama, Ujung Tanah }\end{array}$ & Gurun Laweh & Lubuk Begalung & $\begin{array}{l}\text { - } \text { Ketinggian air } \pm 30 \mathrm{~cm} \mathrm{~s} / \mathrm{d} 50 \mathrm{~cm} \\
\text { - } \text { Mengancam } 9 \mathrm{KK}\end{array}$ \\
\hline 9 & RT 01 RW 03 & Banuaran & Lubuk Begalung & $\begin{array}{l}\text { - } 2 \text { unit rumah hanyut terbawa arus } \\
\text { - } \quad \text { Kerugian : Rp. } 300.000 .000\end{array}$ \\
\hline 10 & Alai Kapalo Koto & Kapalo Koto & Pauh & - Ketinggian air hingga $\pm 30 \mathrm{~s} / \mathrm{d} 50 \mathrm{~cm}$ \\
\hline 11 & RT 02 RW 02 & Beringin & Lubuk Kilangan & $\begin{array}{l}\text { - Ketinggian air } \pm 60 \mathrm{~s} / \mathrm{d} 70 \mathrm{~cm} \\
\text { - } 1 \text { unit rumah hanyut terbawa arus } \\
\text { - Masyarakat terdampak } 25 \mathrm{KK} \text { dan } 10 \\
\text { - Jiwa } \\
\text { Kerugian : } 150.000 .000\end{array}$ \\
\hline 12 & RT 06 RW 01 & Tarantang & Lubuk Kilangan & $\begin{array}{l}\text { - } \text { Ketinggian air } \pm 60 \mathrm{~s} / \mathrm{d} 70 \mathrm{~cm} \\
\text { - } 15 \text { unit rumah terdampak banjir }\end{array}$ \\
\hline 13 & Alai & Alai Parak Kopi & Padang Utara & $\begin{array}{l}\text { - Ketinggian air hingga } \pm 80 \mathrm{~cm} \\
\text { - } 1 \text { unit rumah hanyut terbawa arus. } \\
\text { - } \quad \text { Kerugian: Rp. } 160.000 .000\end{array}$ \\
\hline 14 & $\begin{array}{l}\text { RT 01-05 RW } 11 \\
\text { Kampung Pinang }\end{array}$ & Alai Parak Kopi & Padang Utara & $\begin{array}{l}\text { - } \text { Ketinggian air hingga } \pm 80 \mathrm{~cm} \\
\text { - } \text { Masyarakat terdampak } 650 \mathrm{KK}\end{array}$ \\
\hline 15 & $\begin{array}{l}\text { RT } 13 \text { RW } 03 \text { Kampung } \\
\text { Halaman }\end{array}$ & Alai Parak Kopi & Padang Utara & $\begin{array}{l}\text { - Ketinggian air hingga } \pm 70 \mathrm{~cm} \\
\text { - Masyarakat terdampak } 20 \mathrm{KK}\end{array}$ \\
\hline 16 & RT 03 RW 07 & Seberang Padang & Padang Selatan & - Ketinggian air $\pm 80 \mathrm{~s} / \mathrm{d} 100 \mathrm{~cm}$ \\
\hline
\end{tabular}




\begin{tabular}{|c|c|c|c|c|}
\hline No. & Lokasi Terdampak & Kelurahan & Kecamatan & Keterangan \\
\hline 17 & RT 02 RW 03 & Seberang Palinggam & Padang Selatan & - Ketinggian air $\pm 40 \mathrm{~s} / \mathrm{d} 60 \mathrm{~cm}$ \\
\hline 18 & RT 02 RW 04 & Seberang Padang & Padang Selatan & $\begin{array}{l}\text { - Ketinggian air } \pm 80 \mathrm{~s} / \mathrm{d} 100 \mathrm{~cm} \\
\text { - } 200 \text { rumah terdampak }\end{array}$ \\
\hline 19 & Depan PT Sampoerna & Air Pacah & Koto Tangah & $\begin{array}{l}\text { - } 1 \text { anak hanyut terbawa arus air } \\
\text { (meninggal dunia) }\end{array}$ \\
\hline 20 & $\begin{array}{l}\text { Jembatan Baringin } \\
\text { Panjang } 30 \text { meter } \\
\text { Lebar } 7 \text { meter }\end{array}$ & Baringin & Lubuk Kilangan & $\begin{array}{l}\text { - Terputusnya akses penyebrangan } \\
\text { masyarakat } \\
\text { - Estimasi kerugian } \pm \mathrm{Rp} \\
4.000 .000 .000,-\end{array}$ \\
\hline 21 & $\begin{array}{l}\text { Lubuk Hitam Cindakir } \\
\text { Panjang } 25 \text { meter } \\
\text { Lebar } 5 \text { meter }\end{array}$ & Bungus Timur & $\begin{array}{l}\text { Bungus Teluk } \\
\text { Kabung }\end{array}$ & $\begin{array}{l}\text { - Terputusnya akses penyebrangan } \\
\text { masyarakat } \\
\text { - Estimasi kerugian } \pm \mathrm{Rp} \\
\text { 3.000.000.000,- }\end{array}$ \\
\hline
\end{tabular}

Berdasarkan tabel di atas, menunjukkan bahwa bencana banjir tersebut tergolong besar karena banyaknya daerah yang terdampak dan besarnya kerugian yang ditimbulkan. Oleh karena itu, untuk meminimalisir dampak buruk dari bencana yang terjadi di Kota Padang, BPBD Kota Padang sebagai badan yang mengurus masalah kebencanaan menjalankan fungsi koordinasi. Menurut Awaludin Djamil dalam Hasibuan (2011:86) koordinasi adalah suatu kerja sama antar instansi atau badan sehingga dapat saling mengisi dan mambantu serta melengkapi. Sedangkan menurut Handayaningrat dalam (Prabandary:2017) koordinasi dapat dilihat dari adanya komunikasi, ada atau tidaknya informasi dan teknologi infomasi, kesadaran pentingnya koordinasi antar badan, dan partisipasi pelaksana.Namun, dalam implementasinya peran BPBD masih dinilai kurang optimal dan fungsi koordinasi yang dijalankan masih lemah. Hal ini karena adanya tumpang tindih peran yang dilakukan oleh instansi terkait yang dikarenakan ketidakpahaman mereka terhadap tugas masing-masing sehingga terjadi ketidaksesuaian antara peran yang sebenarnya dengan tindakan yang dilakukan ketika di lapangan. Masalah ini disebabkan oleh tidak adanya sosialisasi yang merata dilakukan oleh BPBD Kota Padang kepada semua pihak yang terlibat dalam kebencanaan.

Oleh karena itu, artikel ini bertujuan untuk mengetahui bagaimana efektivitas kinerja BPBD Kota Padang dalam melakukan koordinasi antar stakeholders penanggulangan bencana di Kota Padang. 


\section{METODOLOGI}

Dalam penelitian ini, jenis penelitian digunakan adalah kualitatif dengan metode deskriptif. Jenis penelitian ini bertujuan untuk menggambarkan dan mendeskripsikan suatu fenomena berdasarkan fakta yang ada dan dikembangkan ke dalam data deskriptif. Informan penelitian ditentukan dengan menggunakan teknik purposive sampling, dimana pemilihan infoman dipilih dengan pertimbangan tertentu,yaitu orang yang dianggap paling tau tentang kebencanaan.Lokasi penelitian dilakukan di kantor BPBD Kota Padang, kantor Dinas Sosial Kota Padang, kantor Pencarian dan Pertolongan Padang, dan Markas Palang Merah Indonesia (PMI) Kota Padang.

Sementara itu, jenis data yang digunakan dalam penelitian ini yaitu data primer dan data sekunder. Data primer dalam penelitian ini adalah keterangan keterangan dari hasil wawancara dengan informan penelitian. Sedangkan data sekunder dalam penelitian ini adalah dokumen dan buku yang terdapat di BPBD Kota Padang. Teknik pengumpulan data dalam penelitian ini dilakukan dengan dua metode yaitu wawancara, dan studi dokumentasi. Uji keabsahan menggunakan triangulasi sumber, yaitu dengan membandingkan hasil wawancara dengan isi dokumen yang berkaitan dengan penelitian. Kemudian untuk teknik analisis data dilakukan dengan cara reduksi data, penyajian data dan penarikan kesimpulan.

\section{HASIL DAN PEMBAHASAN}

Untuk mengetahui efektivitas kinerja BPBD Kota Padang dalam menjalankan fungsi koordinasi antar stakeholders penanggulangan bencana di Kota Padang, peneliti menggunakan 3 indikator pengukuran efektivitas dari teori yang dikemukakan oleh Duncan dalam (Richard M.Steers:1985:53) dan dianalisis berdasarkan hasil wawancara peneliti dengan informan penelitian yang terdiri dari 4 lokasi yang telah penulis tentukan. Adapun indikator penelitian yang telah peneliti analisis dengan hasil wawancara tersebut dapat dideskripsikan sebagai berikut:

\section{Pencapaian tujuan}

Efektivitas kinerja BPBD Kota Padang dalam melakukan koordinasi antar stakeholders penanggulangan bencana dilihat dari pencapaian tujuan dengan memperhatikan sejauh mana hubungan kerja sama antar stakeholders untuk mencapai tujuan koordinasi penanggulangan bencana. Apabila 
tujuan koordinasi dapat dicapai seperti yang diharapkan maka kinerja BPBD Kota Padang dalam menjalankan fungsi koordinasi dapat dikatakan efektif.

Berdasarkan keterangan dari informan penelitian, tujuan dari koordinasi penanggulangan bencana adalah untuk mempercepat penanganan bencana, memudahkan penanganan, dan meringankan beban para korban bencana. Selain itu, tujuan koordinasi adalah menyamakan persepsi masing masing pihak yang terlibat dalam penanggulangan bencana karena masing masing pihak punya peranan yang berbeda beda. Oleh karena itu, efektivitas kinerja BPBD Kota Padang dalam melakukan koordinasi antar stakeholders penanggulangan bencana dapat dilihatdari pencapaian tujuan koordinasi tersebut.Pencapaian tujuan ini dilihat dari pelaksanaan kegiatan yang dilakukan BPBD dengan instansi terkait lainnya.

Dari hasil penelitian,
menunjukkan bahwa BPBD telah
melakukan kerja sama dengan semua
instansi yang terlibat sehingga
penanganan cepatdilakukan karna
adanya kerja sama.Ketika terjadi
bencana, BPBD berkoordinasi dengan
instansi yang bersangkutan seperti
Dinas Sosial dalam hal pemenuhan
kebutuhan pokok para korban, Badan
Nasional Pencarian dan Pertolongan
(BNPP) dalam hal pencarian dan
pertolongan para korban, dan relawan
relawan lain seperti TNI/POLRI, dan
SKPD lainnya.Sehingga dengan ini
tujuan koordinasi
tercapai.Kemudian pada saat keadaan
darurat BPBD juga mempunyai Tim
Reaksi Cepat (TRC) untuk
mengidentifikasi bencana yang terjadi.
Dalam pelaksanaannya dapat dilihat
pada gambar berikut:
pada gambar berikut: 


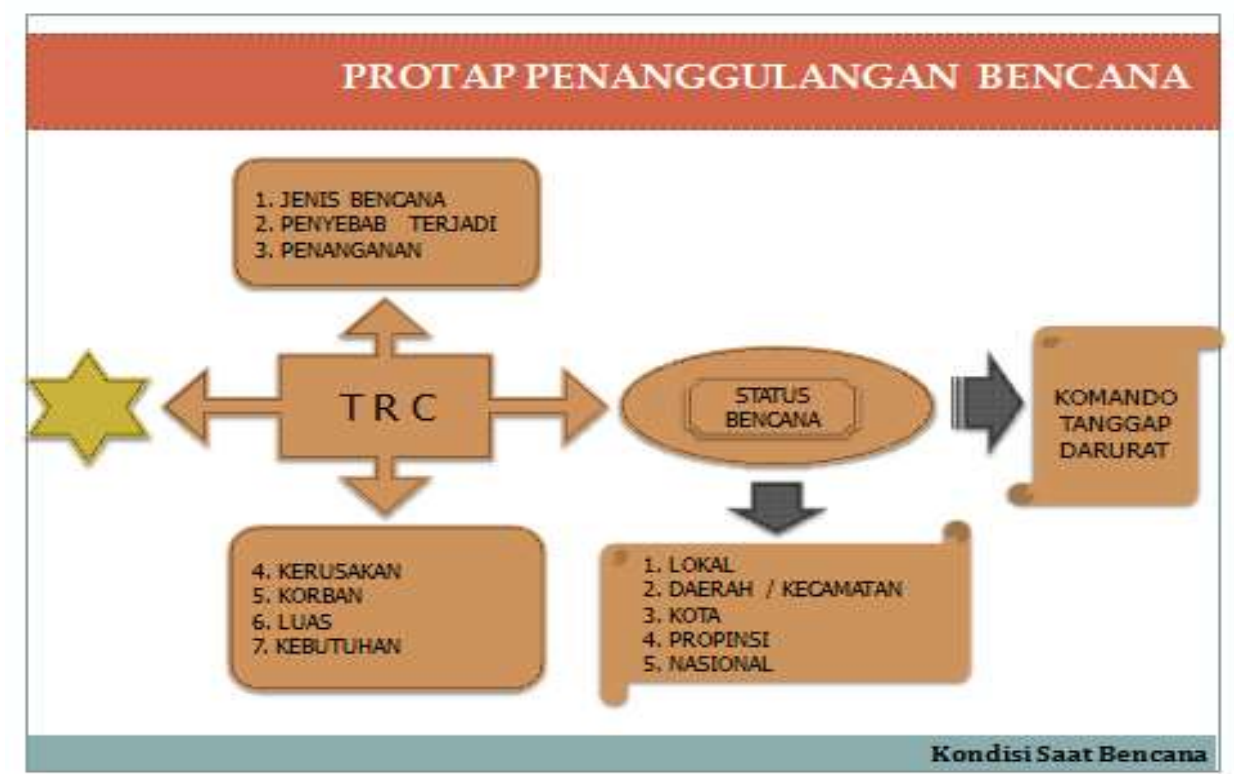

Gambar 1. Protap Penanggulangan Bencana

Sumber : BPBD Kota Padang

Dari gambar di atas dapat dilihat bahwa TRC bertugas untuk mengidentifikasi karakter bencana yang meliputi jenis bencana, penyebab terjadinya bencana, bagaimana penanganan yang akan dilakukan, berapa kerusakan, berapa korban, luas,dan kebutuhan apa yang diperlukan oleh korban. Kemudian melihat status bencana yang meliputi daerah mana yang terkena bencana, provinsi ataupun nasional. Setelah dapat diidentifikasi untuk pelaksanaan penanganan akan dikomandoi oleh komando tanggap darurat.Selain itu BPBD juga ada Pusat Pengendalian Operasi (Pusdalops) yang mana dalam pelaksanaannya diminta masing masing stakeholders mengusulkan personilnya yang diperbantukan di BPBD untuk melaksanakan kegiatan harian pusdalops . Oleh karena itu, hal ini akan berpengaruh terhadap pencapaian tujuan koordinasi.

\section{Integrasi}

Integrasi dilihat dari kemampuan BPBD Kota Padang dalam penggunaan sumber daya manusia dan melakukan komunikasi dengan stakeholders penanggulangan bencana. Integrasi juga berkaitan dengan ketersediaan sarana dan prasarana kerja, pelaksanaan kegiatan dan tujuan. Dari penelitian yang dilakukan,dapat diketahui bahwa komunikasi yang dilakukan antar instansi terkait adalah dengan menggunakan radio dalam hal pembagian tugas dilapangan. Ketika dilapangan BPBD mengomandoi instansi instansi terkait untuk 
melaksanakan penanganan sesuai sector dalam penanggulangan bencana. dengan peranannya masing masing karna BPBD adalah sebagai leading Hal ini dapat dilihat dari alur tanggap darurat seperti gambar berikut :

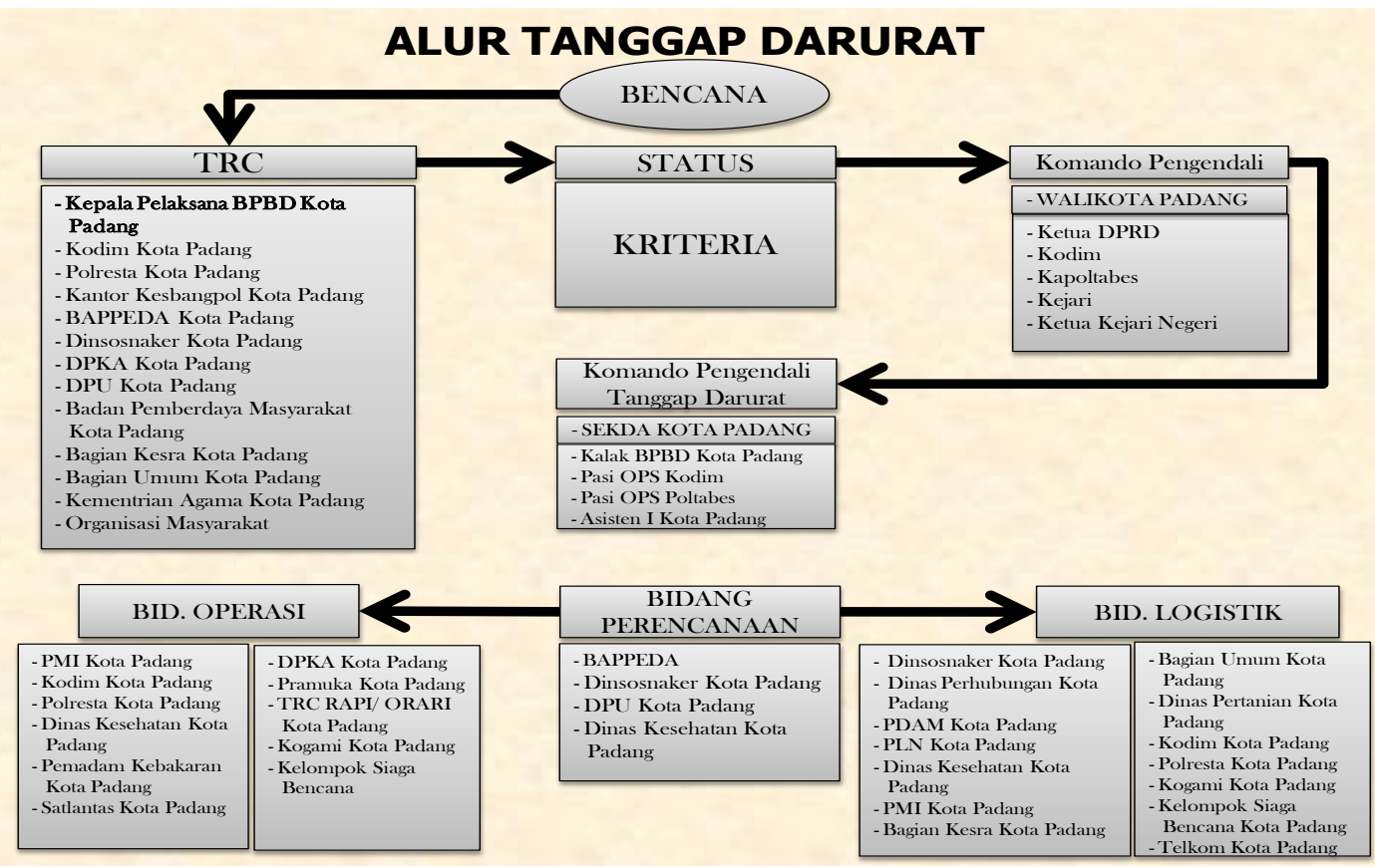

Sumber: BPBD Kota Padang

Gambar 2. Alur koordinasi ketika tanggap darurat bencana

Dari gambar di atas, terlihat bahwa alur koordinasi ketika tanggap darurat sudah jelas.Semua pihak terlibat dalam kebencanaan dan masing masing pihak yang terlibat sudah mempunyai peranan sehingga ketika terjadi bencana semua pihak tau akan tindakan yang seharusnya dilakukan sesuai dengan bidang atau peranan yang telah ditentukan.

Berdasarkan keterangan yang penulis temukan dilapangan, dapat diketahui bahwa BPBD selalu berkomunikasi dengan instansi terkait dan saling menyampaikan informasi kebencanaan dan berkoordinasi untuk melakukan upaya penanganan. Hal ini dapat diketahui dari laporan PUSDALOPS PB Kota Padang terkait penanganan bencana banjir pada bulan November 2018 sebagai berikut :

Tabel 2. Upaya penanganan yang telah dilakukan oleh BPBD Kota Padang

\begin{tabular}{clc}
\hline No & \multicolumn{3}{c}{ Keterangan } \\
\hline 1 & BPBD Kota Padang beserta insan \\
kebencanaan pada tanggal 2 november 2018 \\
pukul 13.00 WIB telah berada dititik lokasi \\
bencana dan melakukan evakuasi terhadap \\
masyarakat yang terdampak. \\
2 Berkoordinasi dengan Dinas/instansi/ \\
lembaga terkait yaitu: TNI, POLRI, BPBD \\
provinsi Sumatera Barat, DAMKAR, Dinas \\
PUPR, Dinas sosial, kecamatan, Padang \\
Rescue, kelurahan, KSB, Pramuka Peduli, \\
Kwarcap Padang, PMI, Tagana, TRC Semen \\
Padang, RBR, RP2B, RAPI, ORARI, KBRC \\
Rescue. \\
BPBD Kota Padang langsung menurunkan 60 \\
orang BPBD ke 20 titik lokasi terdampak \\
bencana untuk melakukan tindakan arahan \\
serta evakuasi warga.
\end{tabular}


Kendaraan yang dibawa BPBD Kota Padang yaitu :

$\checkmark \quad 1$ unit mobil truk serba guna BPBD Kota Padang

$\checkmark \quad 2$ unit mobil ranger BPBD Kota Padang

$\checkmark \quad 1$ unit mobil rescue

$\checkmark \quad 2$ unit Daihatsu peduli

$\checkmark \quad 1$ unit minibus rescue

$\checkmark \quad 2$ unit isuzu panter

$\checkmark \quad 1$ unit minibus isuzu panter

$\checkmark \quad 5$ unit sepeda motor

5 Peralatan yang dibawa yaitu :

$\checkmark \quad 10$ unit perahu karet

$\checkmark \quad 3$ unit Ring Bouy

$\checkmark \quad 9$ unit Chinsaw

$\checkmark \quad 1$ unittali kramantel

$\checkmark \quad 20$ unit radio handy talk

$\checkmark \quad 9$ unit life jacket

6 Tim yang terlibat dalam operasi :

$\checkmark$ BPBD Kota Padang : 20 orang

$\checkmark$ LANTAMAL II PADANG :30 orang

$\checkmark$ LANUD SUTAN SYAHRIR : 15 orang

$\checkmark \quad$ KODIM 0312:87 orang

$\checkmark$ POLRESTA PADANG :70 orang

$\checkmark$ BRIMOB : 30 orang

$\checkmark$ BPBD SUMBAR :10 orang

$\checkmark$ DAMKAR : 10 orang

$\checkmark \quad$ Dinas PUPR : 10 orang

$\checkmark$ Dinas Sosial : 15 orang

$\checkmark$ Kecamatan :35 orang

$\checkmark$ Kelurahan: 70 orang

$\checkmark$ KSB : 35 orang

$\checkmark$ Pramuka Peduli Kwarcap Kota Padang :20 orang

$\checkmark \quad \mathrm{PMI}: 25$ orang

$\checkmark$ Tagana : 30 orang

$\checkmark$ TRC Semen Padang : 10 orang

$\checkmark \quad$ RBR :20 orang

$\checkmark$ RP2B: 5 orang

$\checkmark$ RAPI :16 orang

$\checkmark$ ORARI : 10 orang

$\checkmark \quad$ KBRC Rescue : 2 orang

Sumber : Pusdalops PB Kota Padang

Dari tabel di atas dapat diketahui bahwa BPBD dengan stakeholders penanggulanan bencana telah melakukan integrasi dengan berkoordinasi dalam melakukan upaya penanganan bencana dan penyediaan sarana dan prasarana unruk evakuasi korban.

\section{Adaptasi}

Adaptasi merupakan penyesuaian diri BPBD Kota Padang terhadap peranan yang dimiliki masing masing instansi terkait penanggulangan bencana.Dalam penelitian ini adaptasi dilihat dari bagaimana BPBD menyesuaikan diri dengan peran instansi terkait. Berdasarkan temuan dilapangan diketahui bahwa BPBD telah beradaptasi dengan peranan masing masing instansi terkait. Hal ini terlihat dari bagaimana BPBD menyesuaikan kebutuhan korban dengan peran instansi terkait. Seperti bencana banjir, korban butuh makanan lalu BPBD berkoordinasi dengan Dinas sosial untuk memberikan bantuan makanan. Hal ini dapat dilihat dari bantuan yang diberikan oleh Dinas Sosial kepada korban ketika banjir bulan November 2018 sebagai berikut: Tabel 3. Bantuan dari Dinas Sosial Kota Padang pada bencana banjir 2 november 2018

\begin{tabular}{cl}
\hline No & \multicolumn{1}{c}{ Bantuan yang diberikan } \\
\hline 1 & Tenda \\
2 & Kasur \\
3 & Matras \\
4 & Selimut \\
5 & Baju \\
6 & Kompor/regulator \\
7 & Footwarm \\
8 & Paket Sandang \\
9 & Air Mineral \\
10 & Sembako \\
11 & Family Kit \\
12 & Lampu \\
13 & Terpal \\
\hline Sumber: Dinas Sosial Kota Padang
\end{tabular}


Dari tabel di atas dapat diketahui bahwa dengan adanya koordinasi antara BPBD dengan Dinas sosial maka tujuan koordinasi untuk meringankan beban para korban terpenuhi dengan adanya bantuan bantuan yang diberikan. Meskipun masih ada keluhan dari masyarakat. Hal ini disebabkan karena ketidakpahaman masyarakat dalam permasalahan yang dihadapi.

\section{KESIMPULAN}

Dari hasil penelitian dan pembahasan di atas, dapat disimpulkan bahwa kinerja BPBD Kota Padang dalam melakukan koordinasi antar stakeholders penanggulangan bencana dapat dikatakan efektif. Efektivitas dilihat dari tiga indikator yaitu pencapaian tujuan, integrasi dan adaptasi. Pencapaian tujuan dilihat dari bagaimana pelaksanaan kegiatan penanganan yang dilakukan BPBD bersama stakeholders ketika tanggap darurat bencana untuk mencapai tujuan koordinasi penanggulangan bencana. Hasil penelitian menunjukkan bahwa BPBD bersama insan kebencanaan telah mencapai tujuan koordinasi yaitu meringankan beban para korban karena BPBD dan stakeholders bekerja sama untuk membantu para korban. Kemudian ada Tim Reaksi Cepat (TRC) yang berperan mengidentifikasi suatu bencana sehingga penanganan cepat dilakukan dan tercapainya tujuan koordinasi yaitu mempercepat penanganan.

Integrasi dilihat dari bagaimana penggunaan sumber daya manusia dan komunikasi yang dilakukan oleh BPBD Kota Padang kepada stakeholders penanggulangan bencana serta ketersediaan sarana dan prasarana untuk para korban. Temuan penelitian terkait integrasi menunjukkan bahwa BPBD telah melibatkan semua stakeholders pada setiap kegiatan penanganan dan berkomunikasi dengan semua stakeholders dalam hal pembagian tugas ketika tanggap darurat dengan menggunakan radio dan dengan adanya ketersediaan sarana dan prasaranan untuk evakuasi korban. Sedangkan adaptasi dilihat dari penyesuaian diri BPBD Kota Padang dengan peranan yang dimiliki oleh semua stakeholders yang terlibat. BPBD bersama stakeholders juga menyesuaikan peranan yang dimiliki dengan kebutuhan para korban. Hasil penelitian menunjukkan bahwa BPBD telah menyesuaikan kebutuhan korban dengan peran yang dimiliki masingmasing stakeholders dan BPBD beserta 
stakeholders telah memberikan bantuan yang sesuai dengan apa yang para korban butuhkan.

\section{REKOMENDASI}

Dalam kegiatan koordinasi penanggulangan bencana, BPBD telah melakukan kerja sama dengan semua instansi yang terlibat. Diharapkan

\section{DAFTAR PUSTAKA}

Dokumen Rencana Penanggulangan Bencana Kota Padang 2014 2019.

Hasibuan,Malayu.2011.Manajemen

Dasar, Pengertian dan Masalah. Jakarta: Bumi Aksara.

Peraturan Daerah Nomor 18 Tahun 2008 tentang pembentukan organisasi dan tata kerja Badan Penanggulangan Bencana Daerah Kota Padang.

Peraturan Kepala Badan Nasional Penanggulangan BencanaNomor 15 Tahun 2012 Tentang PUSDALOPS-PB.

Prabandary, $\quad$ N.W., 2017. KOORDINASI ANTAR INSTITUSI DALAM PENGELOLAAN BENDA CAGAR BUDAYA CANDI BOROBUDUR. Adinegara, 6(6), pp.570-581.

Ramdani, E.M., 2015. KOORDINASI OLEH BPBD DALAM PENANGGULANGAN

BENCANA BANJIR DI KABUPATEN BANDUNG. Jurnal Ilmu Administrasi: Media Pengembangan Ilmu dan Praktek Administrasi, 12(3), pp.383-406.

Renstra Badan Penanggulangan Bencana Daerah Kota Padang 2014-2019.

Sadat, A., 2016. Efektivitas Kinerja Badan Penanggulangan Bencana
BPBD Kota Padang terus meningkatkan koordinasi dengan stakeholders penanggulangan bencana agar ketika terjadi bencana penanganan cepat dilakukan dan dapat membantu beban para korban sehingga dapat meminimalisir dampak buruk dari suatu bencana.

Daerah Dalam Pengurangan Resiko Bencana Di Kota Baubau. Jurnal Ilmu Pemerintahan: Kajian Ilmu Pemerintahan dan Politik Daerah, 1(1), pp.1-21.

Steers, Richard. 1985. Efektivitas Organisasi. Jakarta: Erlangga.

Undang-undang Republik Indonesia Nomor 24 tahun 2007 tentang Penanggulangan Bencana. 